\title{
Optimizing selective cerebral perfusion: Deleterious effects of high perfusion pressures
}

\author{
James C. Halstead, MA (Cantab) MB BChir, MD, MRCS (Eng), ${ }^{a}$ Matthias Meier, MD, ${ }^{a}$ Michael Wurm, MD, ${ }^{a}$ \\ Ning Zhang, MD, ${ }^{a}$ David Spielvogel, MD, ${ }^{a}$ Donald Weisz, $\mathrm{PhD},{ }^{\mathrm{b}}$ Carol Bodian, $\mathrm{DrPH},{ }^{\mathrm{c}}$ and Randall B. Griepp, $\mathrm{MD}^{\mathrm{a}}$
}

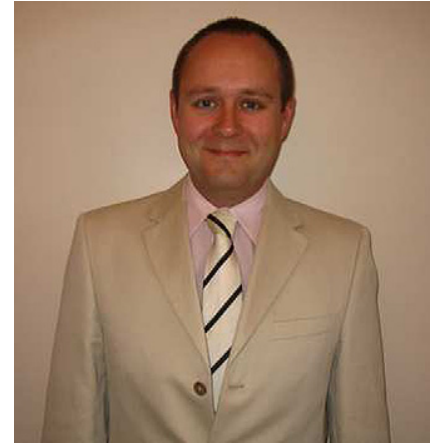

Dr Halstead
From the Departments of Cardiothoracic Surgery, ${ }^{\mathrm{a}}$ Neurosurgery, ${ }^{\mathrm{b}}$ and Biomathematics, ${ }^{\mathrm{c}}$ Mount Sinai School of Medicine, New York, NY.

Supported by National Institutes of Health grant "Cerebral Function After Hypothermic Circulatory Arrest" (GCO ref 90-052).

Received for publication May 25, 2007; revisions received Aug 13, 2007; accepted for publication Sept 6, 2007.

Address for reprints: James C. Halstead MA (Cantab) MB BChir MRCS (Eng), Department of Cardiothoracic Surgery, Mount Sinai School of Medicine, One Gustave L. Levy Place, New York, NY 10029 (E-mail: jameschalstead@yahoo.co.uk).

J Thorac Cardiovasc Surg 2008;135:784-91 $0022-5223 / \$ 34.00$

Copyright $\odot 2008$ by The American Association for Thoracic Surgery

doi:10.1016/j.jtcvs.2007.09.035
Objective: Selective cerebral perfusion is a proven adjunct to hypothermia for neuroprotection in complex aortic surgery. The ideal conditions for the provision of selective cerebral perfusion, however, including optimal perfusion pressure, remain unknown. We investigated the effects of various perfusion pressures during selective cerebral perfusion on cerebral physiology and outcome in a long-term porcine model.

Methods: Thirty piglets $\left(26.3 \pm 1.4 \mathrm{~kg}\right.$ ), cooled to $20^{\circ} \mathrm{C}$ on cardiopulmonary bypass with $\alpha$-stat pH management (mean hematocrit 23.6\%), were randomly assigned to 90 minutes of selective cerebral perfusion at a pressure of 50 (group A), 70 (group B), or 90 (group C) $\mathrm{mm} \mathrm{Hg}$. With fluorescent microspheres and sagittal sinus sampling, cerebral blood flow and cerebral oxygen metabolism were assessed at baseline, after cooling, at two points during selective cerebral perfusion, and for 2 hours after cardiopulmonary bypass. Visual evoked potentials were monitored during recovery. Neurobehavioral scores were assessed blindly from standardized videotaped sessions for 7 postoperative days.

Results: Cerebral blood flow during selective cerebral perfusion was significantly increased by higher-pressure perfusion $(P=.04)$, although all groups sustained similar levels of cerebral oxygen metabolism during selective cerebral perfusion $(P=$ .88). After the end of cardiopulmonary bypass, the cerebral oxygen metabolism increased to above baseline in all groups, with the highest levels seen in group $\mathrm{C}$ $(P=.06)$. Intracranial pressure was significantly higher during selective cerebral perfusion in group $\mathrm{C}(P=.0002)$; visual evoked potentials did not differ among groups. Neurobehavioral scores were significantly better in group A $(P=.0002)$.

Conclusion: Selective cerebral perfusion at $50 \mathrm{~mm} \mathrm{Hg}$ provides neuroprotection superior to that at higher pressures. The increased cerebral blood flow with higherpressure selective cerebral perfusion is associated with cerebral injury, reflected by high post-cardiopulmonary bypass cerebral oxygen metabolism and poorer neurobehavioral recovery.

$\mathrm{S}$ elective antegrade cerebral perfusion (SCP) is gaining widespread popularity as the adjunct of choice along with systemic hypothermia for cerebral protection during aortic arch resection. ${ }^{1,2}$ The optimal parameters for the provision of $\mathrm{SCP}$, however, including perfusion pressure, remain unclear. Under normal physiologic conditions, autoregulation maintains constant levels of cerebral blood flow (CBF) across a wide range of cerebral perfusion pressures. ${ }^{3}$ Unfortunately, hypothermia, cardiopulmonary bypass (CPB) ${ }^{4,5}$ and the cerebrovascular disease and hypertension demonstrable in many patients with aortic aneurysms disturb this mechanism. ${ }^{6,7}$ In the absence of autoregulation, intraoperative CBF becomes pressure dependent. Low levels of flow may result in regional hypoperfusion and cerebral ischemia, ${ }^{8}$ especially in those areas perfused through diseased vessels or in patients with systemic hypertension. Excessive flow may provoke the development of cerebral edema, however, and contribute to an elevated embolic load to the brain. ${ }^{9}$ We sought to assess optimal perfusion pressure during SCP with a long-term porcine model that enables cerebral physiologic assessment and blinded postoperative neurobehavioral analysis. 


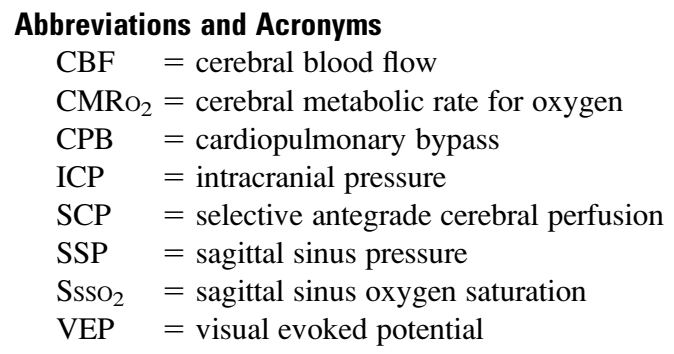

\section{Materials and Methods \\ Study Design}

Thirty juvenile female Yorkshire pigs (approximately 3 months old with a mean weight of $26.3 \pm 1.4 \mathrm{~kg}$ ) were studied (Animal Biotech Industries Inc, Danboro, Pa). The animals were all placed on CPB and cooled to $20^{\circ} \mathrm{C}$, followed by 90 minutes of SCP. In group A, $\mathrm{SCP}$ was carried out at a mean pressure of $50 \mathrm{~mm} \mathrm{Hg}$, in group B at $70 \mathrm{~mm} \mathrm{Hg}$, and in group $\mathrm{C}$ at $90 \mathrm{~mm} \mathrm{Hg}$. Computer-generated randomization was carried out $(\mathrm{CB})$, with individual group allocation revealed at the onset of $\mathrm{CPB}$.

All animals received humane care in accordance with the guidelines from Principles of Laboratory Animal Care formulated by the National Society for Medical Research and with the "Guide for the Care and Use of Laboratory Animals" (www.nap.edu/catalog/ 5140.html). The Mount Sinai Institutional Animal Care and Use Committee approved the protocol for this experiment.

\section{Perioperative Management and Anesthesia}

The perioperative management (including intracranial monitoring and visual evoked potential [VEP] recording) and anesthesia protocols were identical to those previously described. ${ }^{10}$

\section{Operative Technique}

The operative preparation of the animals and the layout of the CPB circuit were identical to those from earlier studies. ${ }^{10}$ Once stable $\mathrm{CPB}$ was established, cooling to $20^{\circ} \mathrm{C}$ was undertaken ( $\alpha$-stat $\mathrm{pH}$ management); cardiotomy suction was not used. CPB was continued for a minimum of 30 minutes after initiation to ensure thorough cooling; the sagittal sinus oxygen saturation $\left(\mathrm{SsSO}_{2}\right)$ values we obtained at the end of cooling and throughout SCP were considerably above baseline (Table 1). The operating room was kept between $18^{\circ} \mathrm{C}$ and $20^{\circ} \mathrm{C}$ to prevent any upward temperature drift.

Just before the commencement of SCP, diastolic cardiac arrest was achieved by adding $1-\mathrm{mEq} / \mathrm{kg}$ potassium chloride to the venous reservoir. Clamps were placed across the ascending aorta and the proximal descending aorta to isolate the arch, and SCP_providing flow to all the arch vessels - was initiated and maintained at a mean pressure (measured in the brachial artery) of 50, 70, or $90 \mathrm{~mm} \mathrm{Hg}$, depending on the group allocation. No flow was provided to the lower body during SCP. Myocardial protection was supplemented by irrigation of the pericardium with iced saline solution (approximately $4^{\circ} \mathrm{C}$ ).

After SCP, the clamps were removed, and CPB with whole-body perfusion was reinstituted. Rewarming was carried through to a brain temperature of $36.5^{\circ} \mathrm{C}$, maintaining a temperature difference of less than $10^{\circ} \mathrm{C}$ between the perfusate and brain and rectal measurements. Cardiac defibrillation was achieved electrically without the need for pharmacologic adjuncts.

\section{CBF and Cerebral Oxygen Metabolism}

Fluorescent microspheres were used to determine $\mathrm{CBF}$ and cerebral metabolic rate for oxygen $\left(\mathrm{CMRO}_{2}\right)$, as reported in previous studies. ${ }^{4,10}$ After the 1-week period of daily neurobehavioral assessment, the animals were killed by exsanguination under anesthesia and their brains were removed.

\section{Hemodynamic and Metabolic Data}

In addition to the injection of microspheres, various physiologic data were collected at the following times: baseline (after the induction of anesthesia but before the initiation of CPB); after 15 and 30 minutes of cooling; after 30, 60, and 90 minutes of SCP; after 15 and 30 minutes of rewarming; and 15 minutes and 2 hours after CPB. The data recorded were as follows: brain and rectal temperatures, mean arterial pressure, intracranial pressure (ICP), sagittal sinus pressure (SSP), $\mathrm{pH}, \mathrm{PCO}_{2}$, arterial oxygen saturation, $\mathrm{SssO}_{2}$, oxygen content, hemoglobin concentration, hematocrit, glucose concentration, and CPB flow (where appropriate).

\section{Behavior and Postoperative Neurologic Outcome}

In the early recovery phase (defined as the first 3 hours after extubation), the animals were scored according to a 6-point scale reflecting both early mental alertness and activity. ${ }^{11}$ In addition, starting on day 2 to allow adequate convalescence, the animals were also taken daily from their holding areas and allowed to explore a larger environment in a specially designed room baited with strategically placed apple pieces. Animals were videotaped, and performance was scored in a blinded manner (ranging from 5 for normal to 0 for coma or death) by a neuroscientist skilled in assessing pig behavior (DW). The videotapes were not identified with the pig's group or day of convalescence to ensure maximal objectivity. Scores were based on gait, balance, and ease of movement.

\section{Statistical Methods}

Hemodynamic and intraoperative variables were compared between groups at baseline with analysis of variance. Later comparisons were based on absolute values or on changes from baseline if deemed more relevant. For data that were consistent with the requisite assumptions, groups were compared by repeated-measures analyses of variance separately for periods of cooling, SCP, rewarming, and post-CPB recovery. Pairwise comparisons, with the Bonferroni multiple testing correction used to control for an overall .05 significance level, were conducted if the corresponding average difference or time-by-group interaction was statistically significant. Other variables were compared by Wilcoxon tests at each time point, or averaged across several days in the case of behavioral scores. Analyses were performed with SAS software (SAS Institute, Inc, Cary, NC).

\section{Results}

\section{Comparability of Experimental Groups}

All animals were examined preoperatively daily by a veterinary team to ensure that they were in normal health before the surgery. The mean \pm SD preoperative weights of the animals 
TABLE 1. Hemodynamic and cardiopulmonary bypass-related data

\begin{tabular}{|c|c|c|c|c|c|c|c|c|c|c|}
\hline $\begin{array}{l}\text { Variable } \\
\text { by group }\end{array}$ & Baseline & $\begin{array}{l}\text { After } 15 \mathrm{~min} \\
\text { cooling }\end{array}$ & $\begin{array}{l}\text { End of } \\
\text { cooling }\end{array}$ & $\begin{array}{l}30 \mathrm{~min} \\
\mathrm{SCP}\end{array}$ & $\begin{array}{l}60 \mathrm{~min} \\
\mathrm{SCP}\end{array}$ & $\begin{array}{l}90 \mathrm{~min} \\
\mathrm{SCP}\end{array}$ & $\begin{array}{l}15 \mathrm{~min} \\
\text { rewarm }\end{array}$ & $\begin{array}{l}30 \mathrm{~min} \\
\text { rewarm }\end{array}$ & $\begin{array}{c}15 \text { min } \\
\text { post CPB }\end{array}$ & $\begin{array}{c}2 \text { h post } \\
\text { CPB }\end{array}$ \\
\hline \multicolumn{11}{|c|}{ Brain temperature $\left({ }^{\circ} \mathrm{C}\right)$} \\
\hline$A$ & $35.6 \pm 0.8$ & $35.6 \pm 0.8$ & $20.0 \pm 0.0$ & $19.8 \pm 0.2$ & $19.8 \pm 0.1$ & $19.8 \pm 0.2$ & $25.6 \pm 1.8$ & $31.7 \pm 2.7$ & $35.3 \pm 0.4$ & $35.6 \pm 1.3$ \\
\hline$B$ & $35.2 \pm 0.5$ & $25.2 \pm 3.9$ & $20.0 \pm 0.0$ & $19.9 \pm 0.1$ & $19.8 \pm 0.1$ & $19.8 \pm 0.2$ & $24.4 \pm 1.5$ & $31.1 \pm 2.6$ & $34.9 \pm 1.1$ & $35.5 \pm 1.3$ \\
\hline C & $35.5 \pm 1.2$ & $23.3 \pm 1.5$ & $20.0 \pm 0.0$ & $19.8 \pm 0.2$ & $19.8 \pm 0.1$ & $19.8 \pm 0.3$ & $25.6 \pm 2.0$ & $33.1 \pm 2.2$ & $35.0 \pm 0.6$ & $35.2 \pm 1.3$ \\
\hline \multicolumn{11}{|c|}{ Mean arterial pressure $(\mathrm{mm} \mathrm{Hg})$} \\
\hline A & $66 \pm 17.5$ & $46 \pm 1.6$ & $46 \pm 2.1$ & $50 \pm 0$ & $50 \pm 0$ & $50 \pm 0$ & $52 \pm 13.6$ & $55 \pm 10.5$ & $52 \pm 8.3$ & $52 \pm 8.6$ \\
\hline$B$ & $58 \pm 7.0$ & $48 \pm 3.9$ & $44 \pm 4.4$ & $70 \pm 0.0$ & $70 \pm 0.3$ & $70 \pm 0.3$ & $46 \pm 8.1$ & $53 \pm 9.5$ & $50 \pm 8.1$ & $54 \pm 7.5$ \\
\hline C & $63 \pm 13.6$ & $45 \pm 5.6$ & $44 \pm 2.0$ & $90 \pm 0.0$ & $90 \pm 0.3$ & $90 \pm 1.3$ & $49 \pm 11.2$ & $59 \pm 16.3$ & $52 \pm 9.4$ & $49 \pm 7.5$ \\
\hline \multicolumn{11}{|c|}{$\mathrm{pH}$ (at $37^{\circ} \mathrm{C}$ ) } \\
\hline$A$ & $7.56 \pm 0.06$ & $7.47 \pm 0.05$ & $7.48 \pm 0.04$ & $7.46 \pm 0.05$ & $7.42 \pm 0.02$ & $7.40 \pm 0.04$ & $7.41 \pm 0.02$ & $7.41 \pm 0.01$ & $7.41 \pm 0.04$ & $7.40 \pm 0.09$ \\
\hline$B$ & $7.58 \pm 0.04$ & $7.46 \pm 0.03$ & $7.47 \pm 0.03$ & $7.42 \pm 0.03$ & $7.39 \pm 0.05$ & $7.39 \pm 0.04$ & $7.43 \pm 0.03$ & $7.44 \pm 0.02$ & $7.45 \pm 0.07$ & $7.38 \pm 0.05$ \\
\hline C & $7.58 \pm 0.06$ & $7.47 \pm 0.08$ & $7.48 \pm 0.09$ & $7.44 \pm 0.06$ & $7.42 \pm 0.02$ & $7.41 \pm 0.05$ & $7.42 \pm 0.04$ & $7.43 \pm 0.05$ & $7.43 \pm 0.08$ & $7.42 \pm 0.05$ \\
\hline \multicolumn{11}{|c|}{$\mathrm{PaCO}_{2}$ (at $37^{\circ} \mathrm{C}, \mathrm{mm} \mathrm{Hg}$ ) } \\
\hline $\mathrm{A}$ & $38.7 \pm 5.7$ & $42.5 \pm 4.8$ & $40.0 \pm 5.5$ & $38.2 \pm 3.0$ & $39.3 \pm 2.9$ & $37.6 \pm 4.2$ & $36.2 \pm 3.4$ & $37.5 \pm 3.2$ & $38.6 \pm 6.6$ & $35.7 \pm 3.8$ \\
\hline$B$ & $35.6 \pm 4.7$ & $42.0 \pm 2.8$ & $38.6 \pm 2.6$ & $41.0 \pm 1.2$ & $40.4 \pm 4.3$ & $37.5 \pm 2.8$ & $36.0 \pm 2.1$ & $38.0 \pm 2.2$ & $34.5 \pm 6.2$ & $39.0 \pm 6.2$ \\
\hline C & $36.4 \pm 4.4$ & $43.0 \pm 8.2$ & $40.7 \pm 9.3$ & $40.6 \pm 6.1$ & $40.1 \pm 4.3$ & $37.9 \pm 6.2$ & $37.3 \pm 5.2$ & $38.6 \pm 4.8$ & $38.0 \pm 8.0$ & $36.6 \pm 4.8$ \\
\hline \multicolumn{11}{|c|}{ Sagittal sinus oxygen saturation (\%) } \\
\hline$A$ & $78.9 \% \pm 7.8 \%$ & $90.7 \% \pm 5.0 \%$ & $92.1 \% \pm 4.1 \%$ & $90.0 \% \pm 5.5 \%$ & $90.5 \% \pm 6.5 \%$ & $89.3 \% \pm 6.8 \%$ & $83.8 \% \pm 5.8 \%$ & $76.0 \% \pm 10.6 \%$ & $75.9 \% \pm 7.1 \%$ & $80.1 \% \pm 8.9 \%$ \\
\hline B & $77.5 \% \pm 6.7 \%$ & $89.0 \% \pm 4.5 \%$ & $89.2 \% \pm 9.2 \%$ & $93.6 \% \pm 5.0 \%$ & $94.3 \% \pm 5.0 \%$ & $95.0 \% \pm 4.2 \%$ & $83.3 \% \pm 7.1 \%$ & $75.7 \% \pm 9.2 \%$ & $77.8 \% \pm 9.0 \%$ & $85.3 \% \pm 6.9 \%$ \\
\hline C & $79.5 \% \pm 4.4 \%$ & $90.4 \% \pm 6.3 \%$ & $93.1 \% \pm 2.4 \%$ & $95.6 \% \pm 3.9 \%$ & $97.3 \% \pm 2.4 \%$ & $96.0 \% \pm 4.9 \%$ & $83.0 \% \pm 6.5 \%$ & $78.2 \% \pm 8.4 \%$ & $73.5 \% \pm 9.9 \%$ & $75.8 \% \pm 8.9 \%$ \\
\hline \multicolumn{11}{|c|}{ Sagittal sinus $\mathrm{P}_{2}(\mathrm{~mm} \mathrm{Hg})$} \\
\hline A & $5 \pm 1.1$ & $3 \pm 1.8$ & $2 \pm 1.9$ & $2 \pm 2.0$ & $2 \pm 1.8$ & $3 \pm 2.8$ & $3 \pm 1.9$ & $4 \pm 2.3$ & $6 \pm 2.7$ & $6 \pm 1.1$ \\
\hline$B$ & $5 \pm 2.2$ & $4 \pm 2.1$ & $4 \pm 2.4$ & $4 \pm 2.4$ & $5 \pm 2.4$ & $5 \pm 2.8$ & $3 \pm 2.1$ & $4 \pm 2.7$ & $6 \pm 3.1$ & $7 \pm 1.6$ \\
\hline C & $4 \pm 2.6$ & $3 \pm 2.4$ & $3 \pm 2.5$ & $6 \pm 4.0$ & $7 \pm 4.5$ & $7 \pm 5.0$ & $4 \pm 3.2$ & $4 \pm 3.2$ & $5 \pm 3.0$ & $6 \pm 3.4$ \\
\hline \multicolumn{11}{|c|}{ Hematocrit $(\%)$} \\
\hline$A$ & $30 \% \pm 3.4 \%$ & $25 \% \pm 2.6 \%$ & $27 \% \pm 4.1 \%$ & $25 \% \pm 3.4 \%$ & $25 \% \pm 3.6 \%$ & $25 \% \pm 3.5 \%$ & $28 \% \pm 2.3 \%$ & $31 \% \pm 2.4 \%$ & $35 \% \pm 4.4 \%$ & $32 \% \pm 3.4 \%$ \\
\hline$B$ & $27 \% \pm 2.8 \%$ & $24 \% \pm 2.2 \%$ & $25 \% \pm 2.3 \%$ & $23 \% \pm 2.7 \%$ & $23 \% \pm 2.3 \%$ & $22 \% \pm 2.5 \%$ & $26 \% \pm 2.8 \%$ & $29 \% \pm 3.3 \%$ & $33 \% \pm 3.5 \%$ & $32 \% \pm 3.9 \%$ \\
\hline C & $28 \% \pm 1.6 \%$ & $25 \% \pm 2.4 \%$ & $24 \% \pm 2.0 \%$ & $23 \% \pm 2.1 \%$ & $23 \% \pm 2.6 \%$ & $23 \% \pm 2.5 \%$ & $28 \% \pm 3.1 \%$ & $32 \% \pm 3.6 \%$ & $37 \% \pm 4.2 \%$ & $33 \% \pm 5.5 \%$ \\
\hline \multicolumn{11}{|c|}{ Cardiopulmonary bypass flow (mL/min) } \\
\hline$A$ & No flow & $1943 \pm 311$ & $1649 \pm 281$ & $402 \pm 381$ & $413 \pm 365$ & $405 \pm 342$ & $1758 \pm 535$ & $1861 \pm 455$ & No flow & No flow \\
\hline$B$ & No flow & $2031 \pm 423$ & $1922 \pm 568$ & $768 \pm 481$ & $831 \pm 484$ & $893 \pm 467$ & $2131 \pm 507$ & $1947 \pm 480$ & No flow & No flow \\
\hline C & No flow & $2028 \pm 363$ & $1940 \pm 411$ & $1463 \pm 1108$ & $1521 \pm 1069$ & $1446 \pm 973$ & $1978 \pm 587$ & $1876 \pm 535$ & No flow & No flow \\
\hline
\end{tabular}

All values are shown as mean \pm SD. Temperature values shown are those recorded from the brain parenchyma. The pH values are for arterial blood. To demonstrate comparability among groups at each stage of the procedure, these variables were compared by four separate repeated measures analyses of variance, one each for the periods of cooling, selective cerebral perfusion, rewarming, and after cardiopulmonary bypass. Apart from the significant differences between groups in mean arterial pressure and cardiopulmonary bypass flow during selective cerebral perfusion, reflecting the design of the experiment, the only other group differences significant at $P<.05$ were for hematocrit during cooling (group-by-time interaction $P=.03$ ), Paco ${ }_{2}$ after cardiopulmonary bypass (group-by-time interaction $P=.04$ ), and sagittal sinus oxygen saturation after cardiopulmonary bypass (between groups $P=.02$ ). 
in each of the 3 groups were similar: group A, $26.7 \pm 1.6 \mathrm{~kg}$; group B, $27.0 \pm 1.4 \mathrm{~kg}$; and group C, $27.4 \pm 1.3 \mathrm{~kg}(P=$ $.57)$.

There were 3 deaths ( 1 in each group) either during the operation or within the first 12 postoperative hours. All were clearly related to technical mishaps. Each subject was replaced in a randomized fashion.

\section{Hemodynamic and CPB-Related Data}

Baseline brain temperature was in close agreement among the three groups (Table 1). Moreover, the temperature changes during cooling, SCP, and rewarming and after $\mathrm{CPB}$ were almost identical among the groups. The baseline mean arterial pressure was not statistically significantly different among groups at baseline or during cooling (Table 1). As intended by the experimental design, however, the three groups displayed distinctly different mean arterial pressures during SCP $(P<.0001)$. Thereafter, during rewarming and after $\mathrm{CPB}$, the levels were in close agreement.

In terms of blood gas management, the $\alpha$-stat strategy was consistently used, and the resulting $\mathrm{pH}$ and $\mathrm{PCO}_{2}$ values were in close agreement among the groups (Table 1). As noted previously, ${ }^{12}$ the pig demonstrates a mild metabolic alkalosis at baseline. Arterial oxygen saturation exceeded 99\% in all animals at every time point. Hematocrit values were also similar in all the groups at baseline (Table 1). There was universal hemodilution during cooling as a result of the circulation of the saline CPB prime. This was followed by progressive hemoconcentration to values above baseline during rewarming and after CPB. There were no significant differences among the groups. No hypoglycemia was encountered in any animal at any time.

CPB flows were similar in the three groups during cooling and rewarming. Again as a consequence of the study design, however, the flows were significantly different during SCP $(P=.007)$.

\section{Cerebral Blood Flow}

As seen in Figure 1, the baseline CBF values of the three groups were similar and fell similarly during cooling. Once SCP was initiated, the different perfusion pressures led to significantly different levels of $\mathrm{CBF}(P=.04)$, with higher perfusion pressures resulting in greater CBFs. After the termination of $\mathrm{CPB}, \mathrm{CBF}$ remained above baseline in all groups. Although the group effect was not statistically significant during this period, $\mathrm{CBF}$ was highest in group $\mathrm{C}$. $\mathrm{CBF}$ assessment 2 hours after CPB showed that the levels had continued to rise in all three groups, to values almost twice those recorded at baseline, although between-group differences were less pronounced.

\section{$\mathrm{CMRo}_{2}$ and Oxygen Extraction}

The baseline $\mathrm{CMRO}_{2}$ values (Figure 2) were in close agreement among the groups and were similar to values observed in previous studies involving the pig model. ${ }^{4,10,12}$ During

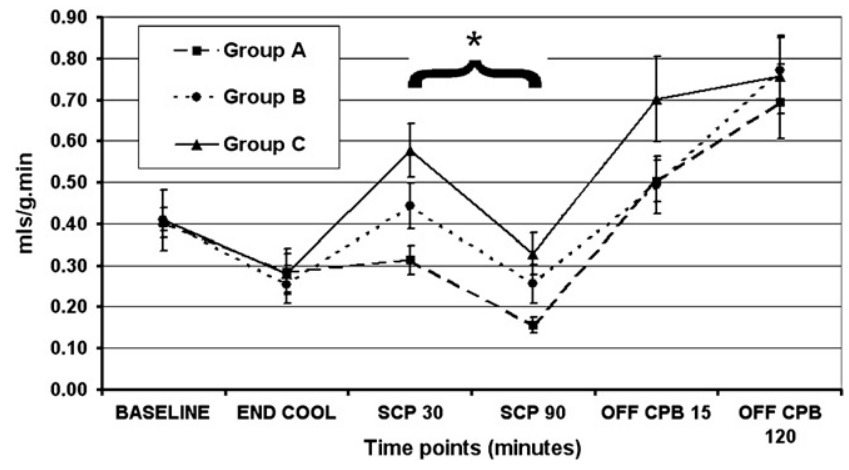

Figure 1. Cerebral blood flow rates (mean \pm SE). BASELINE, After induction of anesthesia but before initiation of cardiopulmonary bypass; END COOL, value at end of cooling; SCP 30 and SCP 90, values after 30 and 90 minutes of selective cerebral perfusion; OFF CPB 15 and OFF CPB 120, values at 15 and 120 minutes after termination of cardiopulmonary bypass. Asterisk denotes statistical significance $(P=.04)$.

cooling, there was a marked decrease in $\mathrm{CMRO}_{2}$ in all groups. Thereafter, during SCP, an initial slight increase compared with the observation at the end of cooling was seen in all groups, again without between-group differences. By the end of SCP, the values in all three groups had fallen to about the same levels as at the end of cooling. After $\mathrm{CPB}, \mathrm{CMRO}_{2}$ values were elevated above baseline in all three groups at both the 15-minute and 2-hour observation points, with the between-group differences coming close to statistical significance $(P=.06)$. The increases were greatest in group $\mathrm{C}$.

The higher $\mathrm{CMRO}_{2}$ seen in group $\mathrm{C}$ during early recovery (15-minute observation) was associated with both higher CBF (Figure 1) and greater oxygen extraction

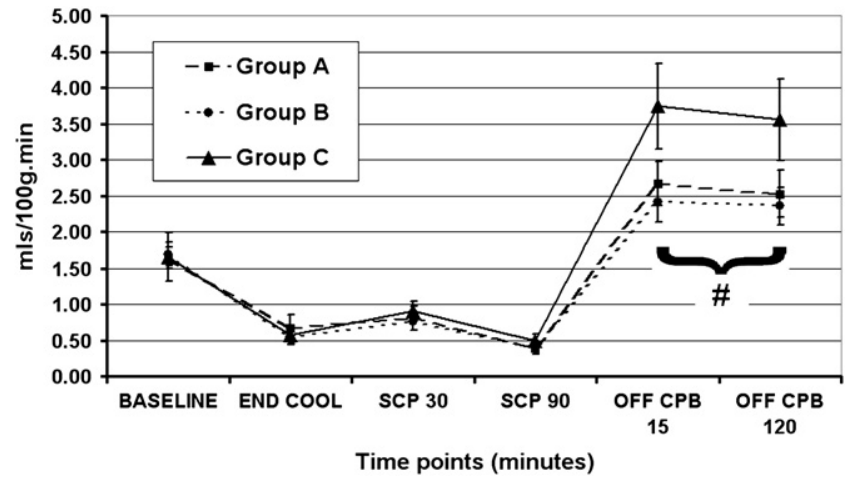

Figure 2. Cerebral metabolic rate for oxygen (mean \pm SE). BASELINE, After induction of anesthesia but before initiation of cardiopulmonary bypass; END COOL, value at end of cooling; SCP 30 and SCP 90, values after $\mathbf{3 0}$ and $\mathbf{9 0}$ minutes of selective cerebral perfusion; OFF CPB 15 and OFF CPB 120, values at 15 and 120 minutes after termination of cardiopulmonary bypass. Hash mark denotes statistical significance $(P=.06)$. 
(Table 1). At the 2-hour observation, CBF did not differ among groups; however, but whereas the $\mathrm{SssO}_{2}$ values for groups A and B were both above baseline, the persistent elevation in $\mathrm{CMRO}_{2}$ in group $\mathrm{C}$ was accompanied by continued high cerebral oxygen extraction, with $\mathrm{SssO}_{2}$ values remaining below baseline and significantly lower than the $\mathrm{SsSO}_{2}$ values in the other groups $(P=.006$ at 2 hours).

\section{Intracranial Pressure}

Values at baseline were low in all groups and remained so during cooling, with no statistically significant differences among the groups (Figure 3). During SCP, however, the values were significantly different $(P=.0002)$ : pairwise analyses showed that group $\mathrm{C}$ differed significantly from groups $\mathrm{A}$ and $\mathrm{B}$ in its elevated ICP values during SCP, attaining a mean level in excess of $10 \mathrm{~mm} \mathrm{Hg}$ at the end of SCP, a level at which we have previously documented impaired recovery. ${ }^{13}$ Group A did not differ significantly from group B. During rewarming, the significant difference between the groups persisted $(P=.003)$, with the same pattern of results in the pairwise comparisons. After discontinuation of CPB, the values of the three groups converged to a level somewhat above baseline. As anticipated, the SSP showed correlation with the ICP, although the modest rise in SSP during SCP in group $\mathrm{C}$ was less pronounced than the significant increase in ICP (Table 1).

\section{Visual Evoked Potentials}

The median cortical wave amplitudes, expressed as percentages of the corresponding waves' amplitudes at baseline,

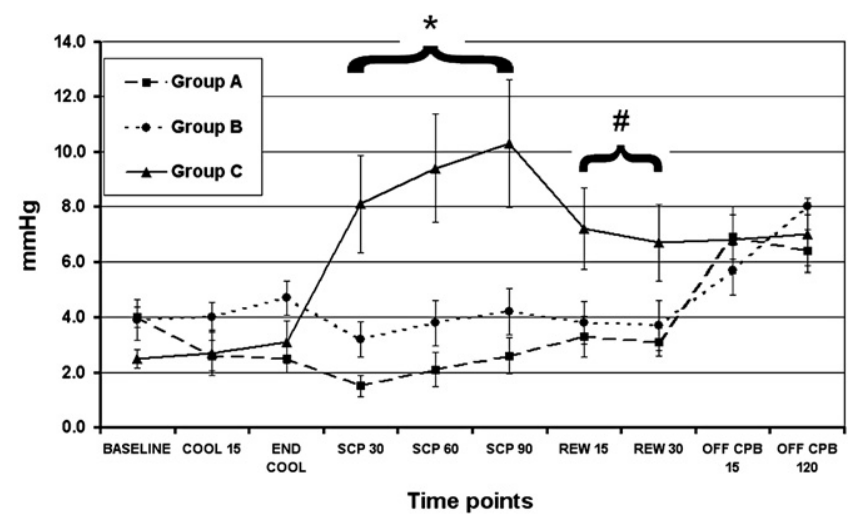

Figure 3. Intracranial pressure (mean values \pm standard error). (mean $\pm \mathrm{SE}$ ). BASELINE, After induction of anesthesia but before initiation of cardiopulmonary bypass; $C O O L$ 15, value after 15 minutes of cooling; END COOL, value at end of cooling; SCP 30, SCP 60, and $S C P$ 90, values after 30,60, and 90 minutes of selective cerebral perfusion; REW 15 and $R E W 30$, values after 15 and 30 minutes of rewarming; OFF CPB 15 and OFF CPB 120, values at 15 and 120 minutes after termination of cardiopulmonary bypass. Asterisk denotes $\boldsymbol{P}=.0002$; hashmark denotes $\boldsymbol{P}=.003$. were close to baseline values by 15 minutes after $\mathrm{CPB}$ in all groups (group A 91\%, group B 76\%, group C 80\%) and had diminished marginally at the 2-hour observation point (group A $75.5 \%$, group B 59\%, group C 64\%). There were no statistically significant differences among the groups.

\section{Early Recovery Scores and Neurobehavioral} Assessment

The median early recovery scores were different among the three groups (group A 6, group B 5, group C 4) for each of the first 3 hours after extubation. These differences, however, did not reach statistical significance for any of the three time points $(P=.18, P=.15$, and $P=.16$, respectively).

The data from the blinded analysis of the daily, videotaped sessions in the maze are shown as Figure 4. The three groups differed significantly in the averages of their scores for days 2 through $7(P=.0002)$. Pairwise analyses show that group A - the group with the lowest perfusion pressure-differed significantly from both group B and group $\mathrm{C}$ but that the difference between groups $\mathrm{B}$ and $\mathrm{C}$ did not reach statistical significance.

\section{Discussion}

\section{Cerebral Autoregulatory Disturbance}

Under normal physiologic conditions, the key mechanisms determining $\mathrm{CBF}$ regulation are autonomous. Myogenic cerebral autoregulation maintains a remarkably constant level of CBF in the face of a range of mean arterial pressures ranging from 50 to $150 \mathrm{~mm} \mathrm{Hg}$, and metabolic autoregulation serves to alter local flow to ensure adequate oxygen delivery to match demand. Unfortunately, during aortic arch surgery there are many factors at play disturbing these precise physiologic balances. Anesthesia, CPB, hypothermia, cerebrovascular disease (a frequent associated finding), and embolization, as well as advanced patient age, can all affect $\mathrm{CBF}$ and its relationship to perfusion pressure. $^{3-8,14}$

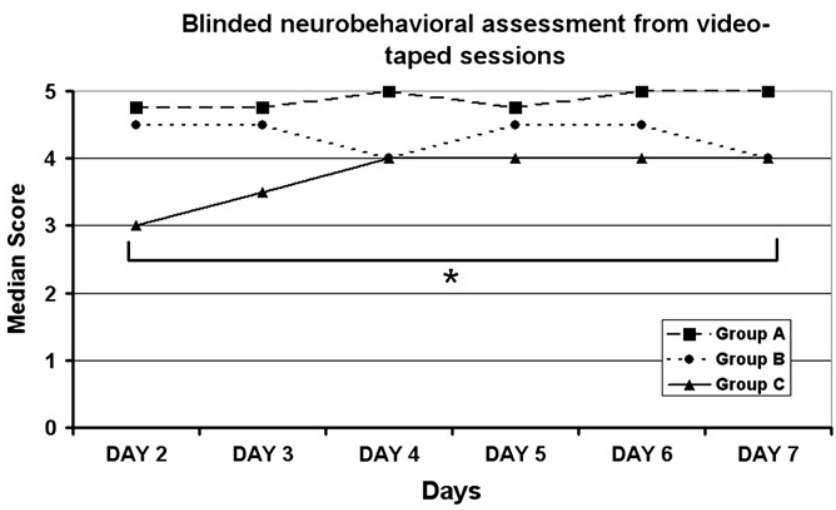

Figure 4. Results from videotaped analysis of pig neurobehavioral performance (median values). Asterisk denotes $\boldsymbol{P}=.0002$. 
Moreover, the use of a limited systemic circulation, in the form of SCP, may have further impact on the integrity of cerebral autoregulation. In this complex setting, in which CBF is likely to become increasingly pressure dependent, the optimal perfusion parameters have yet to be defined.

Inadequate perfusion pressures may leave the brain susceptible to areas of infarction. Inadequate oxygen delivery at lower perfusion pressures is a real concern in the patient cohort undergoing aneurysm repair, because many are hypertensive, are elderly, and have significant atherosclerosis, all of which argue for higher perfusion pressures. But higher pressures in the absence of autoregulation are likely to result in higher CBF, which in turn increases the possibility of embolic damage, a major risk factor in this clinical population. ${ }^{3-9}$

The studies examining the effects of CPB and hypothermia on cerebral autoregulation have produced some conflicting results. Earlier experiments ${ }^{15}$ and clinical data ${ }^{16,17}$ seemed to point toward preserved cerebral autoregulation, even under conditions of hypothermia. Although this has not been resolved, more contemporary results seem to indicate disturbed autoregulation with CPB, especially with profound hypothermia, allowing perfusion pressure to determine CBF. ${ }^{18,19}$ Assuming that the ratio of $\mathrm{CBF}$ to $\mathrm{CMRO}_{2}$ at baseline is ideal, our own studies suggest that there is always some degree of luxury perfusion during $\mathrm{CPB}$ with deep hypothermia but that some of the mechanisms involved in autoregulation nevertheless do seem to operate. Of note in this study, there appears to be active autoregulation in the brain when one compares cerebral perfusion with flow to the remainder of the upper body tissues perfused during SCP. The maximal difference between perfusion at 50 and 90 $\mathrm{mm} \mathrm{Hg}$ was less than 2-fold in the brain but about 4-fold elsewhere, as estimated from total SCP flow.

Previous studies with this model ${ }^{4,10}$ have shown that cerebral perfusion and metabolic characteristics during SCP are not the same as during CPB undertaken with identical parameters. This finding could be due to the unique interaction between the perfused head and neck circulation and the ischemic remainder of the body. Thus cerebral autoregulation during SCP cannot be assumed to conform to that seen with whole-body CPB at comparable temperatures. The only previous study addressing this question $^{20}$ showed that in dogs CBF remained constant as SCP pressure was lowered from 90 to $40 \mathrm{~mm} \mathrm{Hg}$ through reduction in pump flows. Below $40 \mathrm{~mm} \mathrm{Hg}$, however, there was a dramatic fall in $\mathrm{CBF}$ and metabolic rate, suggesting that ischemia was occurring. These studies involved perfusion of the lower body during SCP, however, so one might expect results not dissimilar to those seen with hypothermic $\mathrm{CPB}$.

\section{Impact of SCP Pressure on Cerebral Physiology}

This report is the first to examine the effects of different pressures and flows during SCP with an ischemic lower body and to report effects not only on CBF and metabolism but also on behavioral outcome. The results from our study show that those animals perfused at higher pressures, achieved by increasing CPB flows, have significantly poorer neurobehavioral outcomes according to all our measures. This colors our interpretation of the metabolic and blood flow changes, which we feel must be analyzed in light of their effect on-or correlation with-outcome.

The animals perfused at higher pressures had significantly higher levels of $\mathrm{CBF}$ during SCP. But their $\mathrm{CMRO}_{2}$ levels during SCP were comparable to those of pigs perfused at lower pressures, suggesting a loss of blood flow-metabolism coupling in the high-pressure group, evidence of more severely impaired autoregulation. Results from previous studies ${ }^{10,21}$ suggest that there may be other ways of enhancing $\mathrm{CBF}$ without the deleterious effects of higher-pressure perfusion seen here. Specifically, earlier experiments investigating $\mathrm{pH}$ management ${ }^{10}$ resulted in levels of $\mathrm{CBF}$ in the $\mathrm{pH}$-stat group in excess of those seen with SCP at $90 \mathrm{~mm}$ $\mathrm{Hg}$ in this study, accompanied by elevated $\mathrm{CMRO}_{2}$ levels and correlated with neurobehavioral outcomes no worse than those seen in animals undergoing $\alpha$-stat management. The animals undergoing $\mathrm{pH}$-stat SCP had a low ICP profile, akin to the animals undergoing $\alpha$-stat SCP and the group A and $\mathrm{B}$ animals in this study. The suggestion that elevated CBF may be less harmful if unaccompanied by elevations in ICP is corroborated by other work from our laboratory, including studies in which the elevated $\mathrm{CBF}$ associated with a lower hematocrit during SCP gave rise to both high ICP and poorer outcome.

In the clinical arena, where established cerebrovascular disease is often present, the optimal provision of SCP is even less certain and considerably harder to elucidate. Kazui and colleagues ${ }^{21}$ have provided us some insight through their animal model of established cerebral infarction. Although functional recovery was not assessed, they showed that $\mathrm{pH}-$ stat management confers an improved intraoperative milieu, as attested by lower serum levels of glutamate and malondialdehyde, two products of ischemically mediated brain injury. Furthermore, the same group has shown ischemic histopathologic changes in the brains of mongrel dogs subjected at $25^{\circ} \mathrm{C}$ to either hypothermic circulatory arrest or SCP at $25 \%$ of the normal flow rate relative to those animals perfused at more physiologic levels of $\mathrm{CBF}$, with their attendant higher perfusion pressures. ${ }^{22}$

In our study, animals perfused at higher pressures demonstrated significantly higher levels of ICP both during SCP and during rewarming. The importance of ICP as a prognostic indicator of later neurologic function has been demonstrated previously. ${ }^{13}$ It is not possible to be sure whether the elevated intraoperative ICPs seen in group $\mathrm{C}$ were directly injurious or instead marked some other deleterious mechanism that ultimately resulted in poorer postoperative neurobehavioral function. It is conceivable that ICP could rise as a result of 
microembolic damage, from generalized blood-brain barrier dysfunction with edema formation, or as a direct consequence of higher capillary hydrostatic pressures. In this experiment, the persistently low SSPs in all animals preclude invoking cerebral sinus outflow obstruction as a mechanism. It seems likely that an elevated ICP-regardless of mechanism-contributes to cerebral injury by impairing $\mathrm{CBF}$ during recovery.

There is also a suggestion of elevated post-CPB $\mathrm{CMRO}_{2}$ with higher-pressure SCP. We postulate that this could be a response to intraoperative cerebral injury and that the marginally elevated $\mathrm{CMRO}_{2}$ during recovery reflects attempted reparative efforts by the injured brain. The $\mathrm{SsSO}_{2}$ values in this group remained below baseline at 2 hours, likely reflecting insufficient $\mathrm{CBF}$ being delivered and forcing reliance on increased extraction in an attempt to compensate and provide adequate oxygen delivery. This tenuous situation may precipitate further ischemic damage, contributing to the poorer functional outcome in the high-pressure group. ${ }^{9}$ Others have also commented on the dangers of losing flow-metabolism coupling, because the ability to increase oxygen extraction is not unlimited. ${ }^{23}$ Contrary to an early assumption-by us and by others - that rapid and vigorous recovery of the $\mathrm{CMRO}_{2}$ is evidence of successful cerebral protection, we have found in recent studies that a slower, more gradual recovery from hypothermic cerebral protection often correlates with a better behavioral outcome.

\section{Neurobehavioral Assessment in the Experimental Animal}

The most convincing aspect of the data concerns behavioral outcome, which was scored in several different ways, all of which showed the same result. The completely blinded scoring of daily videotaped behavior, in which the time elapsed since surgery and the experimental group of each pig were not identified, is the most objective system we have yet devised to evaluate postoperative neurologic recovery. This evaluation, which took into account the animals' gait, stability, balance, and ease of movement, showed unequivocally poorer behavioral outcomes in the group perfused at higher pressures during SCP.

\section{Study Limitations and Clinical Recommendations}

Overall, these results suggest that elevated perfusion pressures are not advisable during SCP. Clearly, the avoidance of neurologic injury in the clinical situation is more complex than in this experimental model, and we concede that elevated flow rates-and possibly higher perfusion pressures-may improve the vitality of collateralized watershed regions around areas of cerebral infarction that may be present in patients with atherosclerosis. ${ }^{24,25}$ The increased CBF that occurs with higher-pressure perfusion is also likely to be dangerous, however, increasing the risk of cerebral edema and also enhancing the possibility of embolization of athero- sclerotic debris in patients with aneurysms, a risk not present in this juvenile pig model. As yet, no functional neurologic outcome data are available from experimental studies of SCP after previous focal insults.

Although one cannot extrapolate every detail directly from the experimental to the clinical situation, we emphasize the importance of establishing the ideal preparatory conditions for SCP. In particular, thorough cooling on CPB, reflected by $\mathrm{SssO}_{2}$ levels far above baseline at the end of cooling and during SCP (Table 1), was used here experimentally, and we find jugular venous saturations very useful in our clinical practice, with SCP only initiated once the jugular bulb venous saturation exceeds $90 \%$. In addition, jugular venous saturations can provide - as in this experiment-a useful ongoing reflection of the adequacy of cerebral perfusion. Transcranial Doppler ultrasonography and various systems for monitoring tissue oxygenation are also useful safeguards that may alert the clinical team to inadequate regional perfusion during SCP.

On the basis of our results, we recommend that clinical SCP be undertaken at flows producing pressures between 50 and $70 \mathrm{~mm} \mathrm{Hg}$. This level of perfusion pressure appears to provide blood flow adequate to meet demands, and, in the presence of $\alpha$-stat $\mathrm{pH}$ management, should allow some degree of autoregulation to continue to operate. Higherpressure $\mathrm{SCP}$, although theoretically appealing, is associated with increased $\mathrm{CBF}$, elevated ICP, and poorer behavioral outcome.

\section{References}

1. Di Eusanio M, Schepens MA, Morshuis WJ, Dossche KM, Di Bartolomeo R, Pacini D, et al. Brain protection using selective antegrade cerebral perfusion: a multicenter study. Ann Thorac Surg. 2003;76: 1181-8.

2. Strauch JT, Spielvogel D, Lauten A, Galla JD, Lansman SL, McMurtry K, et al. Technical advances in total aortic arch replacement. Ann Thorac Surg. 2004;77:581-9.

3. Lassen NA. Cerebral blood flow and oxygen consumption in man. Physiol Rev. 1959;39:183-238.

4. Strauch JT, Spielvogel D, Haldenwang PL, Zhang N, Weisz D, Bodian CA, et al. Impact of hypothermic selective cerebral perfusion compared with hypothermic cardiopulmonary bypass on cerebral hemodynamics and metabolism. Eur J Cardiothorac Surg. 2003;24:807-16.

5. Mutch WA, Sutton IR, Teskey JM, Cheang MS, Thomson IR. Cerebral pressure-flow relationship during cardiopulmonary bypass in the dog at normothermia and moderate hypothermia. J Cereb Blood Flow Metab. 1994; 14:510-8.

6. Sungurtekin H, Boston US, Orszulak TA, Cook DJ. Effect of cerebral embolization on regional autoregulation during cardiopulmonary bypass in dogs. Ann Thorac Surg. 2000;69:1130-4.

7. Baumbach GL, Heistad DD. Cerebral circulation in chronic arterial hypertension. Hypertension. 1988;12:89-95.

8. Howard R, Trend P, Russell RW. Clinical features of ischemia in cerebral arterial border zones after periods of reduced cerebral blood flow. Arch Neurol. 1987;44:934-40.

9. O'Dwyer C, Prough DS, Johnston WE. Determinants of cerebral perfusion during cardiopulmonary bypass. J Cardiothorac Vasc Anesth. 1996; 10:54-64.

10. Halstead JC, Spielvogel D, Meier DM, Weisz D, Bodian C, Zhang N, et al. Optimal pH strategy for selective cerebral perfusion. Eur J Cardiothorac Surg. 2005;28:266-73. 
11. Hagl C, Tatton NA, Weisz DJ, Zhang N, Spielvogel D, Shiang HH, et al. Cyclosporine A as a potential neuroprotective agent: a study of prolonged hypothermic circulatory arrest in a chronic porcine model. Eur J Cardiothorac Surg. 2001;19:756-64.

12. Strauch JT, Spielvogel D, Haldenwang PL, Zhang N, Weisz D, Bodian CA, et al. Cooling to 10 degrees $\mathrm{C}$ and treatment with cyclosporine A improve cerebral recovery following prolonged hypothermic circulatory arrest in a chronic porcine model. Eur J Cardiothorac Surg. 2005;27:74-80.

13. Hagl C, Khaladj N, Weisz DJ, Zhang N, Guo LJ, Bodian CA, et al. Impact of high intracranial pressure on neurophysiological recovery and behavior in a chronic porcine model of hypothermic circulatory arrest. Eur J Cardiothorac Surg. 2002;22:510-6.

14. Lee JG, Hudetz AG, Smith JJ, Hillard CJ, Bosnjak ZJ, Kampine JP. The effects of halothane and isoflurane on cerebrocortical microcirculation and autoregulation as assessed by laser-Doppler flowmetry. Anesth Analg. 1994;79:58-65.

15. Murkin JM, Farrar JK, Tweed WA, McKenzie FN, Guiraudon G. Cerebral autoregulation and flow/metabolism coupling during cardiopulmonary bypass: the influence of $\mathrm{PaCO}_{2}$. Anesth Analg. 1987;66:825-32.

16. van der Linden J, Priddy R, Ekroth R, Lincoln C, Pugsley W, Scallan M, et al. Cerebral perfusion and metabolism during profound hypothermia in children. A study of middle cerebral artery ultrasonic variables and cerebral extraction of oxygen. J Thorac Cardiovasc Surg. 1991;102: 103-14.

17. Govier AV, Reves JG, McKay RD, Karp RB, Zorn GL, Morawetz RB, et al. Factors and their influence on regional cerebral blood flow during nonpulsatile cardiopulmonary bypass. Ann Thorac Surg. 1984;38: 592-600.
18. Plochl W, Cook DJ, Orszulak TA, Daly RC. Critical cerebral perfusion pressure during tepid heart operations in dogs. Ann Thorac Surg. 1998; 66:118-24.

19. Schwartz AE, Sandhu AA, Kaplon RJ, Young WL, Jonassen AE, Adams DC, et al. Cerebral blood flow is determined by arterial pressure and not cardiopulmonary bypass flow rate. Ann Thorac Surg. 1995;60: 165-70.

20. Tanaka J, Shiki K, Asou T, Yasui H, Tokunaga K. Cerebral autoregulation during deep hypothermic nonpulsatile cardiopulmonary bypass with selective cerebral perfusion in dogs. J Thorac Cardiovasc Surg. 1988;95:124-32.

21. Ohkura K, Kazui T, Yamamoto S, Yamashita K, Terada H, Washiyama $\mathrm{N}$, et al. Comparison of $\mathrm{pH}$ management during antegrade selective cerebral perfusion in canine models with old cerebral infarction. J Thorac Cardiovasc Surg. 2004;128:378-85.

22. Tanaka H, Kazui T, Sato H, Inoue N, Yamada O, Komatsu S. Experimental study on the optimum flow rate and pressure for selective cerebral perfusion. Ann Thorac Surg. 1995;59:651-7.

23. Philpott JM, Eskew TD, Sun YS, Dennis KJ, Foreman BH, Fairbrother SN, et al. A paradox of cerebral hyperperfusion in the face of cerebral hypotension: the effect of perfusion pressure on cerebral blood flow and metabolism during normothermic cardiopulmonary bypass. J Surg Res. 1998;77:141-9.

24. Bozzao L, Fantozzi LM, Bastianello S, Bozzao A, Fieschi C. Early collateral blood supply and late parenchymal brain damage in patients with middle cerebral artery occlusion. Stroke. 1989;20:735-40.

25. Dirnagl U, Pulsinelli W. Autoregulation of cerebral blood flow in experimental focal brain ischemia. J Cereb Blood Flow Metab. 1990;10: 327-36.

\section{Access to The Journal of Thoracic and Cardiovascular Surgery Online is reserved for print subscribers!}

Full-text access to The Journal of Thoracic and Cardiovascular Surgery Online is available for all print subscribers. To activate your individual online subscription, please visit The Journal of Thoracic and Cardiovascular Surgery Online, point your browser to http://www.mosby.com/itcvs, follow the prompts to activate your online access, and follow the instructions. To activate your account, you will need your subscriber account number, which you can find on your mailing label (note: the number of digits in your subscriber account number varies from 6 to 10). See the example below in which the subscriber account number has been circled:

\section{Sample mailing label}

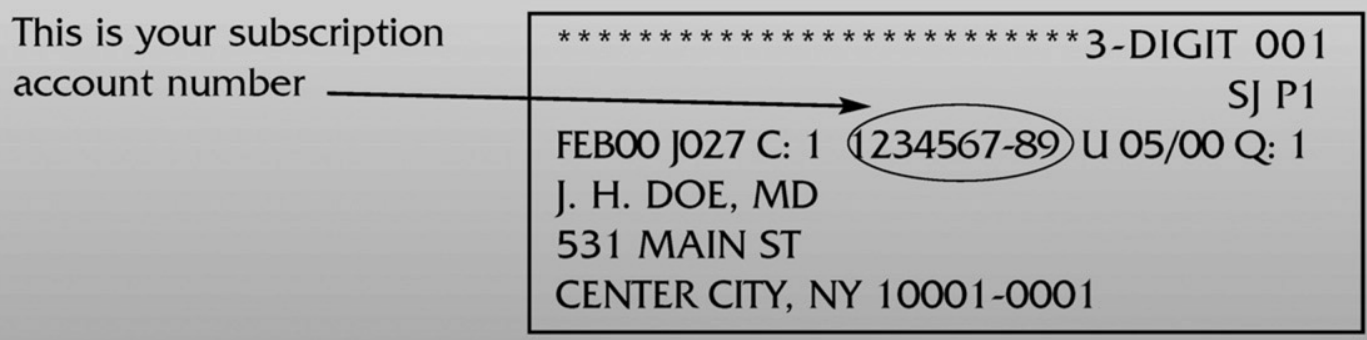

Personal subscriptions to The Journal of Thoracic and Cardiovascular Surgery Online are for individual use only and may not be transferred. Use of The Journal of Thoracic and Cardiovascular Surgery Online is subject to agreement to the terms and conditions as indicated online. 